Kartik Sidhar, MD; Erin Hammer, MD, MPH Department of Family Medicine and Community Health (Drs. Sidhar and Hammer) and Department of Orthopedics and Rehabilitation (Dr. Hammer), University of Wisconsin School of Medicine and Public Health, Madison

Đkartiksidhar@gmail.com

The authors reported no potential conflict of interest relevant to this article.

doi: $10.12788 /$ fp. 0183

\section{How to help runners steer clear of injury}

\section{PRACTICE RECOMMENDATIONS}

$>$ Counsel runners to cross-train, replace shoes regularly, and use shoes with moderate-to-high (8-12 mm) heel-totoe drop. (C)

> Don't discourage running for exercise, as long as it is tolerated, in patients who have osteoarthritis. (C)

> Encourage moderation in running distance and intensity, especially in novice runners. (C)

Strength of recommendation (SOR)

A Good-quality patient-oriented evidence

B Inconsistent or limited-quality patient-oriented evidence

C Consensus, usual practice opinion, disease-oriented evidence, case series
A pproximately 60 million people in the United States run for exercise at least once a calendar year, with approximately 11 million of them running $>100$ days a year. ${ }^{1,2}$ Running is an affordable, convenient, and efficient form of exercise, whose benefits include a decrease in the risk of allcause early mortality, cancer, and diabetes; an improved lipid profile; and better mental health. ${ }^{3}$

However, running is also the cause of a significant percentage of exercise-associated injuries: More than $60 \%$ of runners report overuse injury annually. ${ }^{4}$ Given the high incidence of running-related injury, an important component of primary care is accurately diagnosing and managing such injuries and counseling patients about how to prevent them.

This article reviews risk factors for running-related injury and summarizes evidence-based recommendations for prevention.

\section{CASE}

During a health maintenance examination, Clara K, a 47-yearold woman who is obese (body mass index [BMI], 34) and has bilateral knee osteoarthritis (OA), inquires about establishing a weight-loss strategy. Ms. $\mathrm{K}$ is interested in starting an exercise regimen involving running but is worried about provoking a flare of OA pain.

\section{Risk factors for running injuries}

Several risk factors-some modifiable, others nonmodifiableare associated with running-related injury (TABLE $\mathbf{1}^{4-16}$ ). In addition, research suggests that other variables once thought to be risk factors, such as running surface and the Q-angle (described later), are not associated with running-related injury.

\section{Modifiable risk factors}

- Changes in a training regimen or type of training. Many runners escalate training regimens as their fitness improves. 


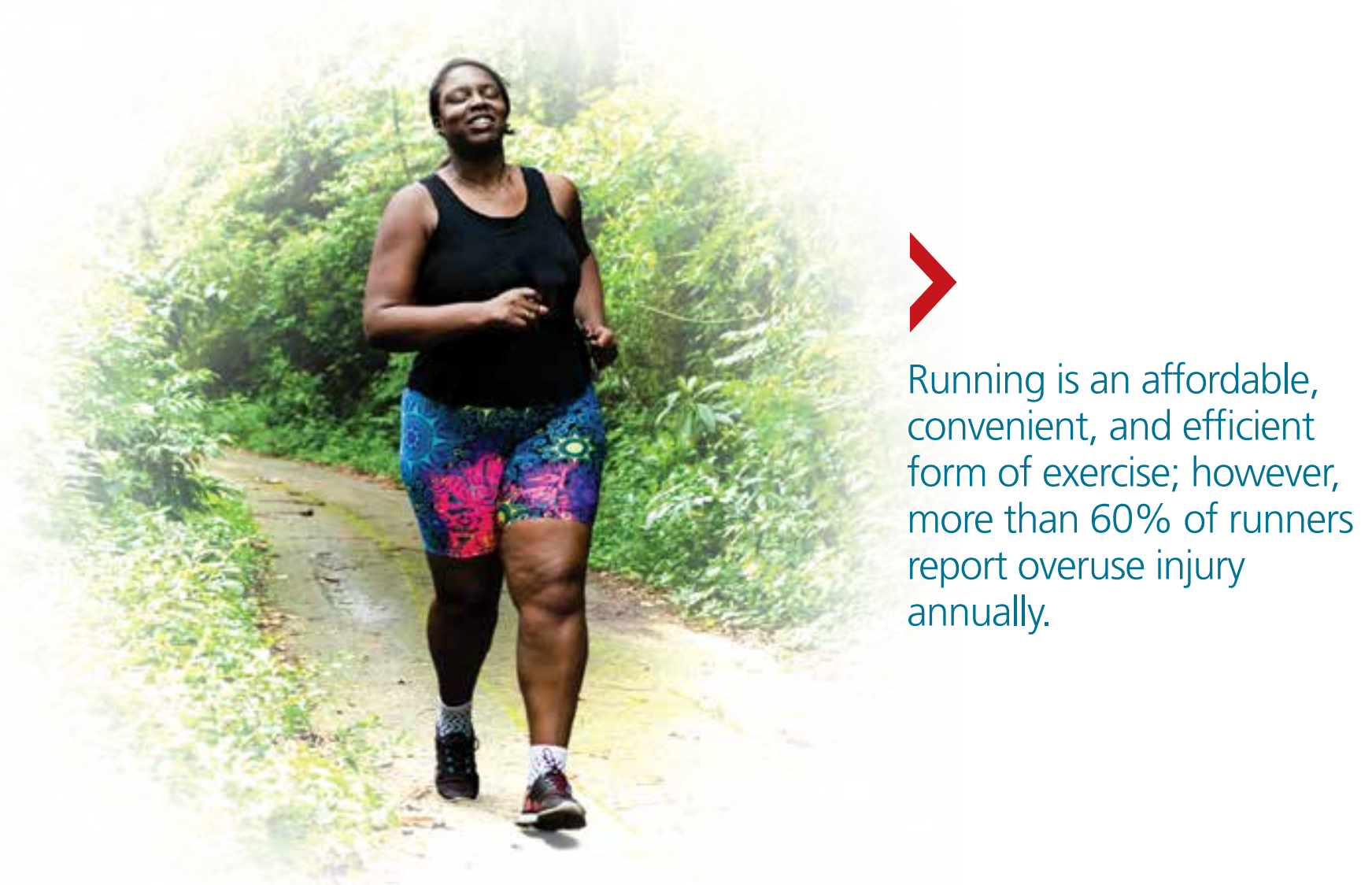

Increasing mileage and changing the type of training (such as introducing hills or interval training) are independent risk factors for sustaining injury. ${ }^{5}$

The traditional recommendation has been for a runner to slowly increase or modify training with a $10 \%$ weekly increase in mileage or intensity. ${ }^{17}$ However, a randomized controlled trial failed to show a lower incidence of injury among amateur runners who adopted a graded exercise program. ${ }^{18}$ Regardless: It is still prudent to recommend a gradual increase in activity, such as taking $\geq 1$ day off between running workouts or starting with a walking or jogging program, especially when there is a history of injury. ${ }^{19}$

IExcessive mileage. Many runners aspire to complete high-mileage runs. There is low-quality evidence demonstrating that high-mileage running, especially $>40$ miles per week, is associated with increased risk of running-related injury. ${ }^{5}$ Injuries that occur with higher mileage are more often those of the hip and hamstring. ${ }^{5}$ A study noted that running $\leq 25$ miles a week was protective against calf injury. ${ }^{6}$

Overall, there is little evidence to show that high-mileage running is associated with increased risk of running-related injury.
However, this is still a risk factor that you should address with patients who have a running program-especially novices and those who ramp up mileage quickly.

Type of surface. Access to running surfaces-concrete, pavement, trails, treadmills, and athletic tracks - varies by time of day and season. Softer surfaces include treadmill, tracks, and trails; harder surfaces include asphalt and concrete.

There are limited data linking running surface with risk of injury. ${ }^{7}$ A study did not find an association between peak impact force based on running surface ${ }^{8}$; the authors hypothesized that runners compensate for a harder surface by making kinematic adjustments to minimize impact. With no strong evidence to link running-related injury to a particular running surface, patients should not be restricted to a softer running surface unless they notice a difference in comfort, because it is likely that they can compensate for a harder surface by adapting their gait.

Patients can therefore be counseled to run locally on sidewalks and neighborhood streets-if safe to do so-instead of obtaining a gym membership or driving to run on a trail. Such reassurance can increase a patient's access to running and reduce barriers to exercise. 
TABLE 1

Real (and refuted) risk factors for running-related injury: How to help patients reduce their risk ${ }^{4-16}$

\begin{tabular}{|c|c|c|}
\hline Risk factor & Magnitude of risk & Recommendation to reduce risk \\
\hline Arch height & $\begin{array}{l}\text { Pes planus and pes cavus can be associated } \\
\text { with increased risk of injury }{ }^{5,7,11-13}\end{array}$ & $\begin{array}{l}\text { Consider prescribing or recommending an orthosis } \\
\text { to reduce pain, although this does not necessarily } \\
\text { reduce the risk of injury }\end{array}$ \\
\hline Sex & $\begin{array}{l}\text { Female runners-particularly those who } \\
\text { are underweight and meet criteria for the } \\
\text { female athlete triad-are at slightly higher } \\
\text { risk of running-related injury, including bone } \\
\text { stress injury }{ }^{4,14}\end{array}$ & $\begin{array}{l}\text { Complete a risk assessment for female runners (as } \\
\text { for all runners) and evaluate them for the female } \\
\text { athlete triad }\end{array}$ \\
\hline $\begin{array}{l}\text { Changes } \\
\text { in training }\end{array}$ & $\begin{array}{l}\text { Changes in the training regimen are } \\
\text { associated with increased risk of running- } \\
\text { related injury }\end{array}$ & $\begin{array}{l}\text { Recommend that any increase in activity that } \\
\text { the patient is planning be gradual; consider } \\
\text { recommending a day off between runs to allow } \\
\text { for recovery-especially when a runner has had a } \\
\text { previous injury }\end{array}$ \\
\hline Mileage & $\begin{array}{l}\text { Higher mileage can be associated with } \\
\text { increased risk of injury }{ }^{5,6}\end{array}$ & $\begin{array}{l}\text { Recommend (especially to novices) running } \\
<40 \text { miles per week (ideally, }<25 \text { miles per week) to } \\
\text { decrease risk of injury }\end{array}$ \\
\hline Surface & $\begin{array}{l}\text { There is no association between running } \\
\text { surface and injury or impact force } e^{7,8}\end{array}$ & $\begin{array}{l}\text { No recommendations for reducing risk } \\
\text { Advise patients that they can run on any surface } \\
\text { they find comfortable or convenient }\end{array}$ \\
\hline Body mass index & $\begin{array}{l}\text { Patients with a higher body mass index } \\
\text { might have a slightly higher risk of running- } \\
\text { related injury } 4,9,10\end{array}$ & $\begin{array}{l}\text { No recommendations for reducing risk } \\
\text { Given the potential benefit of exercise, patients } \\
\text { should not be discouraged from running-the slight } \\
\text { increase in risk of injury notwithstanding }\end{array}$ \\
\hline Osteoarthritis & $\begin{array}{l}\text { There is no strong evidence that } \\
\text { osteoarthritis progresses with, or is } \\
\text { exacerbated by, running }{ }^{15,16}\end{array}$ & $\begin{array}{l}\text { No recommendations for reducing risk } \\
\text { Patients with osteoarthritis who want to run can } \\
\text { be encouraged to do so, as long as they find that } \\
\text { running is comfortable }\end{array}$ \\
\hline
\end{tabular}

BMI. Elevated BMI increases joint contact forces, which might increase risk of pain and injury. ${ }^{20}$ Results of studies investigating the link between BMI and running injury are mixed; some report that, in regard to bone stress injury, overweight BMI (> 25) is a risk factor for male runners and underweight BMI $(<18.5)$ is a risk factor for female runners. ${ }^{4,6} \mathrm{An}$ observational study concluded that, among half-marathon and marathon runners, there was no significant increase in race-related injury, based on BMI. ${ }^{9}$ However, another study showed a higher rate of running-related injury in novice runners who had a higher BMI. ${ }^{10}$ A prospective cohort study found that runners with a higher BMI reported increased knee stiffness, which can place a runner at higher risk of overuse injury. ${ }^{4}$

Although these results conflict, there is consistency in the finding that obese novice runners are likely at increased risk of running-related injury; it is reasonable, therefore, for you to discuss strategies to reduce the risk of other modifiable factors, especially among obese novice runners. Patients with a higher BMI should not be discouraged from running, because exercise in combination with healthy eating habits is essential to decrease the myriad adverse health outcomes associated with obesity.

Female runners with a lower BMI, especially in the presence of other components of the female athlete triad (inadequate nutrition, amenorrhea, and low bone density), should be counseled about their increased risk of bone stress injury. ${ }^{21}$ Notably, a study of female US Navy recruits randomized to receive a trial of dietary supplementation of 
vitamin D plus calcium, or placebo, showed a $21 \%$ lower incidence of bone stress injury in the active-treatment group. ${ }^{22}$ To mitigate risk of injury associated with low BMI and the female athlete triad, therefore, a multidisciplinary approach of nutrition intervention, dietary optimization of vitamin $\mathrm{D}$ and calcium, and, possibly, activity modification should be implemented when appropriate.

I Running gait. A study using 2-dimensional gait analysis to visualize biomechanical running patterns in injured and noninjured runners found that, in regard to mechanical variables, running-related injury was most strongly associated with contralateral pelvic drop. ${ }^{23}$ Gait retraining can be employed to help decrease contralateral pelvic drop. ${ }^{24}$ In addition, pelvic drop is often a result of weak gluteal muscles, and can be improved by doing strengthening exercises at home or with physical therapy.

Longer stride is also associated with running-related injury. ${ }^{25} \mathrm{~A}$ study showed improvement in patellofemoral pain by having runners increase stride rate by $10 \%$, which reduces stride length to a significant degree. ${ }^{25,26}$ These improvements were maintained at 1-month and 3-month follow-up, and required only 1 gait retraining session.

Gait analysis is not feasible in most primary care clinics. Instead, patients who run and (1) in whom pain persists despite more traditional treatments and (2) who have had recurring injury should be referred to a gait lab for analysis, usually by a physical therapist.

\section{Nonmodifiable risk factors}

I Arch height. A high arch (pes cavus) is associated with increased risk of running-related injury, including bone stress injury, Achilles tendinopathy, plantar fasciitis, and patellofemoral pain syndrome. ${ }^{5}$ The mechanism of injury is thought to be increased forefoot loading forces. ${ }^{1}$

A review article showed that patients with pes cavus have reduced pain when using an orthosis, although there is no associated decrease in the risk of injury. ${ }^{5}$ To the contrary, a prospective study concluded that arch height was unrelated to increased risk of running-related injury. ${ }^{7}$
Evidence regarding flat feet (pes planus) and risk of injury is also mixed. Some studies show that pes planus is not associated with increased risk of injury in athletes. ${ }^{12} \mathrm{~A}$ crosssectional study in older patients showed those with pes planus morphology had a higher rate of knee pain and wearing away of medial compartment cartilage. ${ }^{13}$ Because this study comprised only older adults, it is not generalizable to runners-nor can conclusions be drawn about causation, given the cross-sectional nature of the study.

Although a foot orthosis can correct mechanical differences caused by pes planus morphology, there is not enough evidence to conclude that correction results in a lower rate of injury. In sum, data are mixed with regard to arch height as a risk factor for running-related injury.

Patients with pes planus or pes cavus should not be discouraged from running, however. If they experience pain with running, they might benefit from a trial of arch support inserts; or consider referral to an orthotist for evaluation for a custom orthosis.

Sex. Based on a prospective cohort study, female runners have a slightly higher rate of running injury than male counterparts. ${ }^{4}$ Similarly, a study showed that female military members generally had a higher incidence of stress fractures than male military members-specifically, femoral shaft and neck stress fractures. ${ }^{14}$ Runners who fall in the spectrum of the female athlete triad, as described earlier, are particularly vulnerable to bone stress injury. It is reasonable, therefore, to review risk factors for injury with female runners (as it is with all runners), especially those who have sustained a prior running-related injury.

I Increased Q-angle (an obsolete risk factor). The Q-angle is approximated by drawing a line from the anterior superior iliac spine to the patella and a second line from the patella to the tibial tubercle. In males, a normal Q-angle is $14^{\circ}$; in females, $17^{\circ}\left(\mathrm{SD}=4.5^{\circ}\right)$. The Q-angle can be obtained by goniometric or radiographic measurement.

An increased Q-angle had been considered an intrinsic risk factor for running injury but has not been shown to be associated with
A study showed improvement in patellofemoral pain by having runners increase stride rate by $10 \%$, which reduces stride length to a significant degree. 


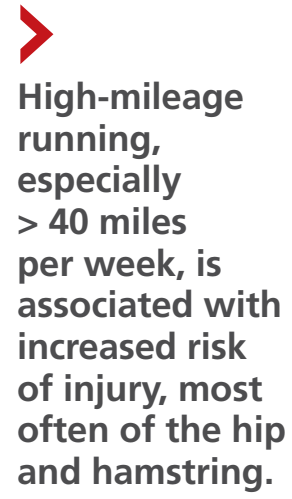

increased risk of running-related injury or patellofemoral pain syndrome. ${ }^{27,28}$ Because the Q-angle is not a clinically relevant tool in assessing risk of injury, do not routinely measure it or include it in risk-factor counseling.

-OA. Based on a systematic review of observational studies, data are inconclusive with regard to whether running contributes to, or is protective against, knee OA. ${ }^{15}$ In a large cohort study, running (1) was protective against development of hip OA and (2) decreased the risk of requiring hip replacement. ${ }^{29}$ This finding was supported by animal-model research that concluded that it is inactivity that results in thinning of articular cartilage. ${ }^{29}$ In addition, a systematic review of randomized controlled trials concluded that knee joint-loading exercises are not harmful to articular cartilage (this is low-quality evidence, however). ${ }^{16}$

Given that there are no high-quality studies suggesting that running contributes to or exacerbates $\mathrm{OA}$, patients with $\mathrm{OA}$ can be counseled to start or continue running as tolerated because the health benefit of running likely outweighs risk. Patients with preexisting moderate-to-severe OA might report knee and hip pain that is already exacerbated by certain activities; if a high-impact activity, such as running, makes that pain worse, exercise counseling that you provide can be tailored to include lower-impact alternatives, such as swimming, cycling, or an elliptical workout.

\section{CASE}

In response to Ms. K's interest in beginning an exercise regimen that includes running, you perform a complete routine pre-participation evaluation and appropriate cardiac screening. You discuss risk factors for running injury, focusing on modifiable risk factors.

Ms. $K$ is perimenopausal but reports a history of regular menstrual cycles. She eats a relatively well-balanced diet. You advise that her BMI should not restrict her from incorporating running into her fitness regimen. Also, you reassure her that she should not restrict running based on a diagnosis of OA; instead, you advise her to monitor her symptoms and reconsider her program if running makes her knee pain worse.
At this point, Ms. $K$ is ready to run. She tells you that, based on your guidance, she feels more comfortable and safe starting a running program.

\section{Preventing injury}

After reviewing risk factors for running-related injury with patients, encourage other evidence-based methods of reducing that risk.

\section{Shoes}

The running shoe industry offers a variety of running shoes, from minimalist shoes to cushioned stability shoes that vary based on the amount of cushioning, level of motion control, and amount of heel-to-toe drop. With so many options, new runners might wonder which shoes can reduce their risk of injury and how they should select a pair.

I Stability. A characteristic of running shoes promoted by the industry is their stability: ie, their motion control. Stability shoes are marketed to runners who overpronate and therefore limit motion to prevent overpronation. The benefit of stability shoes, or stability insoles, is unclear. ${ }^{30} \mathrm{~A}$ randomized controlled trial showed that, in runners who overpronate, motion-control shoes reduced their risk of injury. ${ }^{31}$ However, another study assessed whether shoes that had been "prescribed" based on foot morphology and stride reduced the risk of injury (compared to neutral, cushioned shoes) and found no change in the incidence of soft-tissue injury. ${ }^{32}$ Given no strong evidence to suggest otherwise, runners can be advised to buy shoes based on comfort rather than on foot morphology or running stride.

- Heel-to-toe drop. Another component of shoe variability is heel-to-toe drop (the height difference between heel and forefoot). A study suggests that moderate-to-high (8-12 mm) heel-to-toe drop is associated with a reduced risk of running injury. ${ }^{33}$ Barefoot running shoes, which, typically, have no heel-to-toe drop, are associated with increased risk of injury-specifically, foot stress fracture (especially in runners who are even moderately overweight). ${ }^{34,35}$

IShoe age and shoe wear can be modified to reduce injury. There is evidence that 
TABLE 2

Keep patients running safely with this running shoe guidance

\begin{tabular}{l|l|l}
\hline Variable & Comment & Recommendation \\
\hline Age & Cushioning in running shoes decreases with age & Consider replacing shoes every 12 mo \\
\hline Wear & $\begin{array}{l}\text { Approximately } 50 \% \text { of cushioning is lost by 300- } \\
500 \text { miles of wear, which can lead to increased } \\
\text { risk of running-related injury }\end{array}$ & Replace shoes after 300-500 miles of running \\
\hline Heel-to-toe drop & $\begin{array}{l}\text { Low to no heel-to-toe drop is associated with } \\
\text { increased risk of injury in regular runners }\end{array}$ & $\begin{array}{l}\text { Recommend running shoes that have a moderate- } \\
\text { to-high (8-12 mm) heel-to-toe drop } \\
\text { Advise against minimalist or so-called barefoot } \\
\text { running shoes, especially in overweight patients }\end{array}$ \\
\hline $\begin{array}{l}\text { Stability and motion } \\
\text { control }\end{array}$ & $\begin{array}{l}\text { Certain running shoes are intended to prevent or } \\
\text { correct overpronation during running stride }\end{array}$ & $\begin{array}{l}\text { Evidence is inconsistent that motion-control shoes } \\
\text { decrease the risk of running-related injury } \\
\text { Runners should try several pairs of shoes and wear } \\
\text { the pair that feels most comfortable }\end{array}$ \\
\hline
\end{tabular}

running shoes lose approximately $50 \%$ of cushioning after 300 to 500 miles of use. ${ }^{36}$ Another study found that rotating running shoes-ideally, different types or brandscan lead to fewer running-related injuries. ${ }^{37}$

In general, patients can be counseled to use shoes that feel comfortable, as long as they replace them regularly (TABLE 2). Runners can also consider alternating pairs of different running shoes between runs. Overweight runners should avoid minimally cushioned and low heel-to-toe drop running shoes.

\section{Cross-training}

Cross-training exercises for runners include cycling, an elliptical workout, swimming, and weightlifting. Incorporating cross-training can be protective against running injury because cross-training requires different movement patterns, prevents overuse, and equalizes muscle imbalances that occur with running. ${ }^{7}$ In addition, replacing running with a cross-training activity can decrease weekly running time and mileage, which can further reduce risk of running-related injury. ${ }^{7}$ Runners-especially higher-mileage runners-should be encouraged to incorporate cross-training into their workout regimen to decrease their risk of injury.

I Stretching. The authors of a Cochrane review concluded that there is no significant reduction in injury associated with hamstring or gastrocnemius stretching. ${ }^{32}$ A small randomized, controlled, crossover study concluded that participants subjectively felt their performance was better when warmups included stretching. ${ }^{38}$ This perceived improvement in performance was similar between groups who completed dynamic or static stretching. However, no difference was noted in flexibility or objective performance between groups who stretched or did not stretch before activity.

Although there is no supporting evidence that stretching reduces the risk of injury, stretching is a low-risk intervention. Because stretching might provide subjective benefit to runners, you need not discourage patients from including this activity in their running program. JFP

CORRESPONDENCE

Kartik Sidhar, MD, 15370 Huff Way, Brookfield, WI, 53005; kartiksidhar@gmail.com

\footnotetext{
References

1. Brown CR Jr. Common injuries from running. In: Imboden JB, Hellerman, DB, Stone JH, eds. Current Diagnosis \& Treatment: Rheumatology. 3rd ed. McGraw-Hill; 2013.

2. Lange D. Running \& jogging - statistic and facts. Statista Web site. November 16, 2020. Accessed March 28, 2021. www.statista.com/ topics/1743/running-and-jogging/

3. Warburton DER, Bredin SSD. Health benefits of physical activity: a systematic review of current systematic reviews. Curr Opin Cardiol. 2017;32:541-556. doi:10.1097/HCO.0000000000000437

4. Messier SP, Martin DF, Mihalko SL, et al. A 2-year prospective cohort study of overuse running injuries: The Runners and Injury Longitudinal Study (TRAILS). Am J Sports Med. 2018;46: 2211-2221. doi:10.1177/0363546518773755

5. Fields KB, Sykes JC, Walker KM, et al. Prevention of running injuries. Curr Sports Med Rep. 2010;9:176-182. doi:10.1249/ JSR.0b013e3181de7ec5

6. van der Worp MP, ten Haaf DSM, van Cingel R. Injuries in runners; a systematic review on risk factors and sex differences. PLoS
} 
One. 2015;10:1-18. doi:10.1371/journal.pone.0114937

7. Taunton JE, Ryan MB, Clement DB, et al. A prospective study of running injuries: the Vancouver Sun Run "In Training" clinics. BrJ Sports Med. 2003;37:239-244. doi:10.1136/bjsm.37.3.239

8. Dixon SJ, Collop AC, Batt ME. Surface effects on ground reaction forces and lower extremity kinematics in running. Med Sci Sports Exerc. 2000;32:1919-1926. doi:10.1097/00005768-200011000-00016

9. Vadeboncoeur TF, Silvers SM, Taylor WC, et al. Impact of a high body mass index on lower extremity injury in marathon/half-marathon participants. JPhys Act Health. 2012;9:96-103. doi:10.1123/jpah.9.1.96

10. Buist I, Bredeweg SW. Higher risk of injury in overweight novice runners. Br J Sports Med. 2011;45:338. http://dx.doi.org/10.1136/ bjsm.2011.084038.79

11. Cowan DN, Jones BH, Robinson JR. Foot morphologic characteristics and risk of Exercise-related injury. Arch Fam Med. 1993;2:773-777. doi:10.1001/archfami.2.7.773

12. Michelson JD, Durant DM, McFarland E. The injury risk associated with pes planus in athletes. Foot Ankle Int. 2002;23:629-633. doi: $10.1177 / 107110070202300708$

13. Gross KD, Felson DT, Niu J, et al. Association of flat feet with knee pain and cartilage damage in older adults. Arthritis Care Res (Hoboken). 2011;63:937-944. doi:10.1002/acr.20431

14. Waterman BR, Gun B, Bader JO, et al. Epidemiology of lower extremity stress fractures in the United States military. Mil Med. 2016;181:1308-1313. doi:10.7205/MILMED-D-15-00571

15. Timmins KA, Leech RD, Batt ME, et al. Running and knee osteoarthritis: a systematic review and meta-analysis. Am J Sports Med. 2017;45:1447-1457. doi:10.1177/0363546516657531

16. Bricca A, Juhl CB, Steultjens M, et al. Impact of exercise on articular cartilage in people at risk of, or with established, knee osteoarthritis: a systematic review of randomised controlled trials. $\mathrm{Br}$ J Sports Med. 2019;53:940-947. doi:10.1136/bjsports-2017-098661

17. Johnston CAM, Taunton JE, Lloyd-Smith DR, et al. Preventing running injuries. Practical approach for family doctors. Can Fam Physician. 2003;49:1101-1109.

18. Buist I, Bredeweg SW, van Mechelen W, et al. No effect of a graded training program on the number of running-related injuries in novice runners: a randomized controlled trial. Am J Sports Med. 2008;36:33-39. doi:10.1177/0363546507307505

19. Warden SJ, Davis IS, Fredericson M. Management and prevention of bone stress injuries in long-distance runners. J Orthop Sports Phys Ther. 2014;44:749-765. doi:10.2519/jospt.2014.5334

20. Kim N, Browning RC, Lerner ZF. The effects of pediatric obesity on patellofemoral joint contact force during walking. Gait Posture. 2019;73:209-214. doi:10.1016/j.gaitpost.2019.07.307

21. Tenforde AS, Kraus E, Fredericson M. Bone stress injuries in runners. Phys Med Rehabil Clin NAm. 2016;27:139-149. doi:10.1016/j. pmr.2015.08.008

22. Lappe J, Cullen D, Haynatzki G, et al. Calcium and vitamin D supplementation decreases incidence of stress fractures in female navy recruits. J Bone Miner Res. 2008;23:741-749. doi:10.1359/ jbmr.080102

23. Bramah C, Preece SJ, Gill N, et al. Is there a pathological gait associated with common soft tissue running injuries? Am J Sports Med. 2018;46:3023-3031. doi:10.1177/0363546518793657
24. Willy RW, Scholz PT, Davis IS. Mirror gait retraining for the treatment of patellofemoral pain in female runners. Clin Biomech (Bristol Avon). 2012;27:1045-1051. doi:10.1016/j. clinbiomech.2012.07.011

25. Schubert AG, Kempf J, Heiderscheit BC. Influence of stride frequency and length on running mechanics: a systematic review. Sports Health. 2014;6:210-217. doi:10.1177/1941738113508544

26. Bramah C, Preece SJ, Gill N et al. A 10\% increase in step rate improves running kinematics and clinical outcomes in runners with patellofemoral pain at 4 weeks and 3 months. Am J Sports Med. 2019;47:3406-3413. doi: 10.1177/0363546519879693

27. Ramskov D, Jensen ML, Obling K, et al. No association between $\mathrm{q}$-angle and foot posture with running-related injuries: a 10 week prospective follow-up study. Int J Sports Phys Ther. 2013;8: 407-415.

28. Almeida GPL, Silva AP, França FJR, et al. Q-angle in patellofemoral pain: relationship with dynamic knee valgus, hip abductor torque, pain and function. Rev Bras Ortop. 2016;51:181-186. doi:10.1016/j.rboe.2016.01.010

29. Williams PT. Effects of running and walking on osteoarthritis and hip replacement risk. Med Sci Sports Exerc. 2013;45:1292-1297. doi:10.1249/MSS.0b013e3182885f26

30. Nigg BM, Baltich J, Hoerzer S, et al. Running shoes and running injuries: mythbusting and a proposal for two new paradigms: 'Preferred movement path' and 'comfort filter' Br J Sports Med. 2015;49:1290-1294. doi:10.1136/bjsports-2015-095054

31. Malisoux L, Chambon N, Delattre N, et al. Injury risk in runners using standard or motion control shoes: a randomised controlled trial with participant and assessor blinding. Br J Sports Med. 2016;50:481-487. doi:10.1136/bjsports-2015-095031

32. Yeung SS, Yeung EW, Gillespie LD. Interventions for preventing lower limb soft-tissue running injuries. Cochrane Database Syst Rev. 2011(7):CD001256. doi:10.1002/14651858.cd001256.pub2

33. Malisoux L, Chambon N, Urhausen A, et al. Influence of the heel-to-toe drop of standard cushioned running shoes on injury risk in leisure-time runners: a randomized controlled trial with 6-month follow-up. Am J Sports Med. 2016;44:2933-2940. doi:10.1177/0363546516654690

34. Ryan M, Elashi $M$, Newsham-West $R$, et al. Examining injury risk and pain perception in runners using minimalist footwear. Br J Sports Med. 2014;48:1257-1262. doi:10.1136/ bjsports-2012-092061

35. Fuller JT, Thewlis D, Buckley JD, et al.. Body mass and weekly training distance influence the pain and injuries experienced by runners using minimalist shoes: a randomized controlled trial. $A m$ I Sports Med. 2017;45:1162-1170. doi:10.1177/0363546516682497

36. Cook SD, Kester MA, Brunet ME. Shock absorption characteristics of running shoes. Am J Sports Med. 1985;13:248-253. doi. org/10.1177/036354658501300406

37. Malisoux L, Ramesh J, Mann R, et al. Can parallel use of different running shoes decrease running-related injury risk? Scand J Med Sci Sport. 2015;25:110-115. doi:10.1111/sms.12154

38. Blazevich AJ, Gill ND, Kvorning T, et al. No effect of muscle stretching within a full, dynamic warm-up on athletic performance. Med Sci Sports Exerc. 2018;50:1258-1266. doi:10.1249/ MSS.0000000000001539

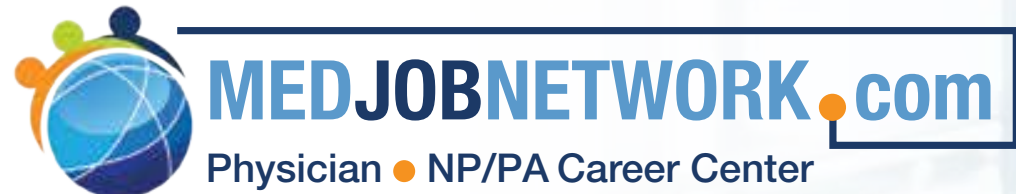

\section{The first mobile job board for Physicians, NPs, and PAs}

\section{Mobile Job Searches - access MedJobNetwork.com on the go from your smartphone or tablet}

Advanced Search Capabilities - search for jobs by specialty, job title, geographic location, employer, and more

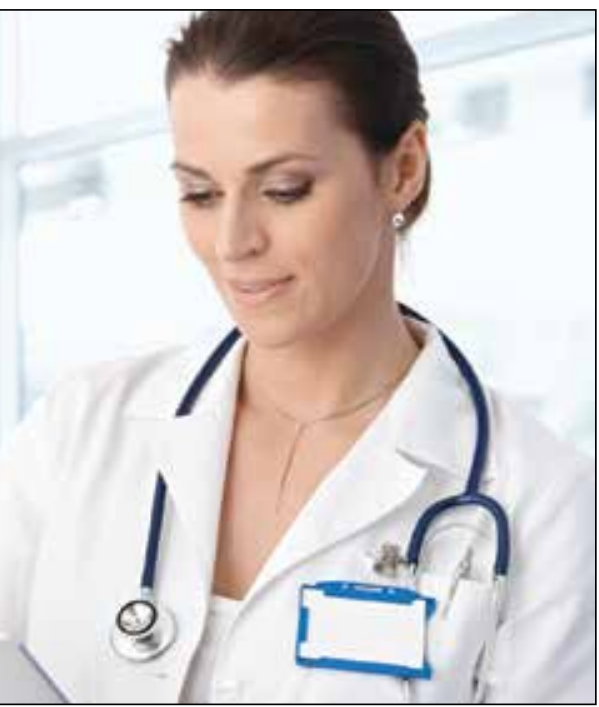

